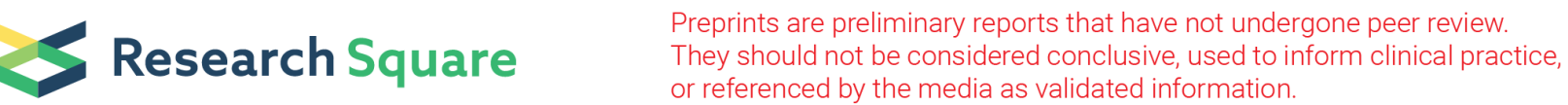

\section{Hypertension Experience of Foreign-Born West African Immigrant Women in the United States: Access to and Utilization of Health Services}

Assumpta Onyinye Ude ( $\nabla$ onyiigeorge@gmail.com )

National Institutes of Health https://orcid.org/0000-0002-3161-7690

Michael Schwab

Walden University

\section{Research}

Keywords: Hypertension, Care services utilization, Health care providers, West-African born immigrants, Access, Cultural competence, Foreign-born-adult immigrants, Women, Health insurance

Posted Date: September 24th, 2020

DOI: https://doi.org/10.21203/rs.3.rs-74897/v1

License: (c) (i) This work is licensed under a Creative Commons Attribution 4.0 International License.

Read Full License 


\section{Abstract}

\section{Background}

Hypertension is a major risk factor for cardiovascular disease and the leading cause of premature deaths in the United States. Hypertension is a commonly reported chronic disease in foreign-born-adult immigrants living in the United States, and psychosocial-cultural factors such as lack of health insurance and poor transportation services have been reported particularly among foreign-born immigrant women with hypertension and other chronic diseases. However, little is known about the socio-cultural factors that influence access to and utilization of hypertension health services in West-African-born immigrant women in the United States.

Methods

This study utilized a qualitative design with a phenomenological approach to interview a purposeful sample of fifteen West-African-born immigrant women that reported diagnosis of hypertension (12 with health insurance and 3 without health insurance) in the Washington District of Columbia Metropolitan area. The Patient Centered Access to Health Care Model guided the conceptual framework of the study. Thematic analysis was used to identify patterns and generate categories and themes.

Results

Five themes emerged from the analysis: Health Insurance Coverage, Frequency of Hypertension Care Visits, Interaction with HCP, Culturally Sensitive HCP, and HTN Self-Care Incentives. Eighty percent of participants had medical insurance and transportation services, but delayed seeking HTN care because their health care providers did not listen to their concerns or discuss their preferences before prescribing treatment. More than 60 percent of the women reported that clinicians did not listen to their concerns or provide culturally appropriate guidance during their visits.

\section{Conclusions}

These findings could be helpful for larger scale studies, or smaller comparative studies in other regions of the United States. Cultural competence training should be included in the continuing education curriculum of healthcare providers serving the West-African-born immigrant population.

\section{Background}

Hypertension (HTN) - sustained systolic blood pressure (BP) above $130 \mathrm{mmHg}$ and a diastolic BP above $80 \mathrm{mmHg}$ - is a major but controllable risk factor for kidney failure and cardiovascular disease (CVD) [1, 2]. It is the leading cause of stroke, myocardial infarction, ischemic cardiomyopathy and premature deaths in the United States (US); it has high prevalence in most African countries [1,3], and it is commonly reported in foreign-born adult immigrants living in the United States. About $45 \%$ of US adults have HTN and, of these, $42 \%$ are non-Hispanic African-American (AA) and $43 \%$ are women $[1,6]$. The 
national self-reported HTN survey did not report specific HTN rates among US adults born in Africa [1, 45], but other studies have reported a high rate of HTN among West-African-born immigrant (WABI) women particularly those who have lived in the United States for more than ten years [6-10]. One important factor that contributes to this high rate of HTN is psycho-social factors, such as neighborhood, poor access to care, specifically among newly arrived immigrants $[1,2,11-14,23,25]$. Distance to health facilities, lack of transportation, lack of health insurance and the high cost of co-payment also affect immigrants' health-seeking behavior and the utilization of health services include [12-17, 23-24]. WABI women with CVD face more socio-cultural barriers to health care services utilization than AA born in the United States [9-10, 18-19] but to date, there are no published studies examining the experiences of WABI women regarding access to and utilization of HTN health services.

\section{Methods}

\section{Aim, design and setting}

The study utilized a qualitative design (phenomenological approach) to explore the experiences of a purposeful convenience sample of WABI women living in the Washington District of

Columbia metropolitan area regarding access and utilization of hypertension health services. The researcher, a clinician born in West-Africa established relationships with organizations that served the West-African communities to discuss the purpose of the study. Participants were recruited from business centers, churches, health fairs, after flyers were distributed to various West-African immigrant community events.

The patient-centered access to health care model contributed to the conceptual framework that guided the design of the interview questions regarding access and utilization of health care services $[12,20$, 21].The research questions were: 1 .What is the experience of WABI in accessing and utilizing health care for HTN? II. What do WABI women believe should be the components of a successful HTN education program or services?

\section{Participants}

The Institutional Review Board of Walden University approved the study in accordance with Walden University's dissertation research policy. Twenty women were recruited between December 2017 and March 2018. Inclusion criteria were: (a) West-African-born immigrant women (b) aged 18-65, (c) selfreported diagnosis of HTN, (d) non-pregnant, (e) fluent in English and (f) a length of stay in the US of at least one year.

Interviews were conducted between April 2018 and May 2018. All participants received a wallet-size BP log card and \$5 Raza international phone calling card as a gift for participating, as well as instructions on how to use the logbook after completion of the interview. The researcher's personal experience was 
bracketed in a reflexive manner by identifying and ignoring her preconceptions and biases throughout the research process [22].

\section{Data Collection}

All the study participants provided written consent. Demographic information was obtained from the participants and selected questions outlined in Figure1(from 40-item interview questionnaire used in the study) examined access to and utilization of HTN health services. Demographic data included current age, age on arrival in the United States, country of birth, state of residence in the United States, fluency in English, occupation, level of education, health insurance status, diagnosis of HTN, having a biological parent, grandparent or sibling with HTN. One-on-one telephone and face-to-face interviews were conducted and audio-recorded in the location of the participants' preference. Notes of all the direct quotes from participants were taken during the interview and maintained in a reflexive journal. Data saturation was reached after fifteen of the twenty women who signed a consent form completed the interview. The average length of time for individual interviews was 45 minutes.

Thematic analysis was utilized to identify, interpret patterns, meaning within the interview transcripts and generate categories and themes [21,22]. Audio-record responses and the memo/notes taken during the interview were transcribed and stored in electronic Microsoft Word database secured in a passwordprotected folder. A manual search of the transcript for narratives, phrases, and keywords was used to generate meaningful codes, which were used to establish themes and sub-themes. Furthermore, peer debriefing was employed by sending samples of the best four interview transcripts for expert review to confirm data saturation.

Conscientious bracketing of any interfering thoughts and potential bias was employed in the interpretation of the participants' answers to open-ended questions and developed themes. A professional colleague with qualitative research expertise also cross-examined the codes and themes.

\section{Results}

\section{Demographics}

WABI women $(n=15)$ completed the interview. All the participants in the study had reported a diagnosis of HTN and had either a parent, grandparent or sibling with a history of HTN. As shown in the summary of selected demographic characteristics in Table 1, the mean age of participants was 47.5 years. A majority of the women $(67 \%, n=10)$ were between $51-65$ years of age. Their length of stay in the United States for the majority of the women $(97 \%, \mathrm{n}=14)$ was more than five years. Five of the women were less than 26 years of age when they came to the United States. Twelve of the women were born in Nigeria and Cameroun and three were born in Sierra Leone, Liberia, and Ghana. This was a highly educated sample; 14 of the 15 women had either college or post-college degree. Twelve of those with at least a college degree worked in a health-related profession. Thirteen of the women had either private or federal health insurance while two women had no health insurance. 
Table 1.Participant Demographics

$(n=15)$ Mean age 47.5 


\begin{tabular}{|c|c|c|c|}
\hline Variable & Category & $\mathbf{N}$ & $\%$ \\
\hline \multirow[t]{3}{*}{ Age } & $30-40$ years & 3 & 20 \\
\hline & $41-50$ years & 2 & 13 \\
\hline & $51-65$ years & 10 & 67 \\
\hline \multirow[t]{3}{*}{ Age upon arrival to the United States } & $18-25$ years & 5 & 33 \\
\hline & $26-45$ years & 8 & 53 \\
\hline & $46-65$ years & 2 & 13 \\
\hline \multirow[t]{5}{*}{ Country of Birth (West Africa) } & Nigeria & 7 & 47 \\
\hline & Liberia & 1 & 7 \\
\hline & Cameroon & 5 & 33 \\
\hline & Sierra Leone & 1 & 7 \\
\hline & Ghana & 1 & 7 \\
\hline \multirow[t]{2}{*}{ State of Residence } & Maryland & 14 & 93 \\
\hline & Washington DC & 1 & 7 \\
\hline \multirow[t]{2}{*}{ Length of Residence in the United States } & Less than 5 years & 1 & 7 \\
\hline & More than 5 years & 14 & 93 \\
\hline \multirow[t]{3}{*}{ Level of Education } & High School & 1 & 7 \\
\hline & College & 8 & 53 \\
\hline & Postgraduate & 6 & 40 \\
\hline \multirow[t]{2}{*}{ Insurance Status } & Has Health Insurance & 12 & 80 \\
\hline & No Health Insurance & 3 & 20 \\
\hline
\end{tabular}




\section{Experience with HCP and Utilization of HTN services}

Table 2 shows the primary themes that described the women's perception of good utilization and access to HTN care and successful HTN health services that include health insurance coverage; interaction with HCP; frequency of health care visits; culturally congruent HCP and HTN self-care incentives. Many of the women had medical insurance but did not seek HTN health services primarily because they were dissatisfied with the quality of care and communication.

Table 2. Selected Research Questions and Primary Themes

\section{Research Questions}

What is the experience of WABI women in accessing and utilizing healthcare for HTN

\section{Primary Themes}

Health Insurance Coverage

Frequency of HTN

Care Visits

Interaction with $\mathrm{HCP}$

Culturally Sensitive HCP

HTN Self-Care Incentives
What do WABI women believe should be the components of successful HTN education programs or services?

Table 3 shows the main factors reported by participants related to their experiences accessing and using HTN health care services. Eighty percent of the women had health insurance and lived 10-30 minutes walking or driving distance to their HCP facility. Many of them chose their current HCP because of the convenient location of their clinics.

Eighty-seven percent had an HCP who could manage their HTN, but most reported accessing care primarily for annual checkups. About $53 \%$ of those with health insurance and regular HCP had utilized a hospital emergency room(ER) or Urgent Care in the past year. More than $60 \%$ of the women were either not satisfied with their overall care, or reported that clinicians did not listen to their concerns or provide culturally appropriate guidance during their visits.

Table 3. Factors relevant to accessing and utilizing hypertension health care services 


\begin{tabular}{|c|c|c|c|c|c|c|c|c|c|c|c|c|c|c|c|c|}
\hline $\begin{array}{l}\text { Participant } \\
\text { Number }\end{array}$ & 1 & 2 & 3 & 4 & 5 & 6 & 7 & 8 & 9 & 10 & 11 & 12 & 13 & 14 & 15 & $n$ \\
\hline $\begin{array}{l}\text { Has health } \\
\text { insurance }\end{array}$ & $X$ & $X$ & $x$ & $x$ & $x$ & $x$ & & $x$ & & & $x$ & $x$ & $x$ & $x$ & $x$ & 12 \\
\hline $\begin{array}{l}\text { Difficulty with } \\
\text { cardiologist } \\
\text { appointment }\end{array}$ & $X$ & $x$ & & & & $x$ & $x$ & & $x$ & $x$ & & & & & $x$ & 7 \\
\hline $\begin{array}{l}\text { Went to } \\
\text { ER/urgent in } \\
\text { past one year }\end{array}$ & $x$ & $x$ & & & $x$ & $x$ & & $x$ & $x$ & $X$ & & & & & $x$ & 8 \\
\hline $\begin{array}{l}\text { Primary HCP } \\
\text { treats HTN }\end{array}$ & $x$ & $x$ & $x$ & $x$ & $x$ & $x$ & & & $x$ & $x$ & $x$ & $x$ & $x$ & $x$ & $x$ & 13 \\
\hline $\begin{array}{l}\text { Drives less than } \\
\text { one hour to HCP } \\
\text { visit }\end{array}$ & $X$ & $x$ & $x$ & $x$ & $X$ & & & $x$ & & $x$ & $x$ & $X$ & $x$ & $x$ & & 11 \\
\hline $\begin{array}{l}\text { HCP listens and } \\
\text { gives enough } \\
\text { time during visit }\end{array}$ & & & $x$ & $x$ & $x$ & & & & & & & $x$ & $x$ & & & 5 \\
\hline $\begin{array}{l}\text { Referred to a } \\
\text { cardiologist in } \\
\text { past one year }\end{array}$ & $x$ & $X$ & $x$ & & & & & & & & & & & & $x$ & 4 \\
\hline $\begin{array}{l}\text { Satisfied with } \\
\text { current HTN } \\
\text { provider care }\end{array}$ & & & $x$ & $x$ & $x$ & $x$ & & & $x$ & $x$ & & $x$ & $x$ & & $x$ & 9 \\
\hline $\begin{array}{l}\text { Satisfied with } \\
\text { overall HTN } \\
\text { care }\end{array}$ & & & $X$ & $X$ & $X$ & & & & & & & $X$ & $X$ & & & 5 \\
\hline
\end{tabular}

\section{Access and Utilization of HTN services}

\section{Theme 1:Negative Experience with Health Care Providers and Poor Quality of Care}

Subtheme 1. HCPs do not listen, spend enough time, or give attention. All the women thought it is necessary to see a HCP routinely for HTN checkup and to see a cardiologist at least once a year but felt disconnected from their HCP during visits, and subsequently went to the ER for HTN care. Many of the women including a physician said their previous and current HCPs were too busy and would not listen or interact with them when they voiced their concerns. Many reported that their HCP rushed and were in a hurry during their visits. One of the women said:

"I stopped seeing doctors for HTN; it is only if I go to the ER for other things that they check my BP."I have noticed that lately maybe in the last 2 years my doctor has become very busy and had less time to listen to my concerns; I feel providers don't have enough time to sit to listen to what the patient is experiencing." 
Another participant said that she was not able to speak up when discussing her HTN care with HCP. "She believes that HCP should initiate an interactive discussion during visit. "I believe one should be allowed to speak up when you have a question."Similarly, another woman expressed her dissatisfaction with HCP's lack of eye contact during her visit. The woman reported that she cancelled her subsequent appointments with that HCP because during her last visit, the HCP focused on the computer screen as she said: "It looks like you are 'shrinking'Shrinking is a medical jargon HCP use at times in reference to a reduction in a patient's Body Mass Index calculated with the patient weight and height which participant did not understand because the HCP could not clarify.

Subtheme 2. Medications don't work. In further description of access to HCP, one participant did not keep many of her HTN check-up appointments and expressed that HCP did not pay attention to her personal health behaviors before prescribing BP medications that did not help in controlling their BP.

"I only went to my doctor because she may not continue to refill my prescription. I was taking hibiscus tea with glucosamine/chondroitin but could not share this with my doctor as she was not open to listening to me."

Another participant expressed similar experience with HCP visit: The whole goal when you see the doctors are to put you on medications that do not work."'They want to do the quick fix like give another prescription."

\section{Theme 2: Components and Improvement of Hypertension Program and Services}

Subtheme 3. Need for more interactive and culturally sensitive care. Many of the women valued culturally sensitive providers that are willing to have a dialogue with them regarding their test results and $\mathrm{BP}$ readings. The women preferred culturally competent HCP that asked for their input and feedback in treatment decision making and development of the plan of care.They wished to have alternative dietary recommendations with African cultural appeal instead of the Dietary Approach to Stop Hypertension (DASH) diet with American food examples that WABI women may not enjoy cooking or eating. For example, one of the women expressed her experience with a HCP that asked if she was on a DASH diet and recommended:

"Ask me about the food I like first not just saying DASH diet. Ask me if for example, I eat cassava leaves; do not put too many coconut oil or peanut butter. Look at my foods and see if I can adjust it."

Subtheme 4. Better education, training, communication and consideration of ethnic preferences. Many of the women valued health education, quick feedback, a shared decision-making approach, and provision of personalized care. One of the participants said a quality program should have HCPs that can educate patients on alternative HTN treatment remedies:

"For example, I googled 'what happens when you take hibiscus tea and glucosamine supplement', and found out that you cannot take hibiscus tea with anything that has Motrin or any medicine for inflammation as it increases BP. I had to google it, but a HCP should discuss this." 
Two of the women thought an ideal HTN program is good interaction and engaging communication between patients, their nurse and doctors. One said: "A place where HCP listen and communicate well with patients and open to answer their questions and encourage them to take responsibility for their health."The other reported: "This is not my country I came here I did not know much about this BP so I prefer a doctor that can listen to me and educate me about this illness."

Two women made suggestions regarding having HTN programs with staff who understand WABI culture and beliefs. "Doctors with experience in tropical medicine or had worked or lived in West-Africa would be very appropriate and ideal." "I would like a program that would first assess my background"

\section{Discussion}

This study revealed that these WABI women - most of them college-educated with health insurance - did not seek HTN health service regularly and did not utilize the services of their HCP primarily because of the poor quality of care they received. This is contrary to previous findings that attributed low health care services utilization among immigrants to 'health illiteracy', 'lack of health insurance' [12, 16, 8-9], or 'awareness of available health care services' as a determinant of regular utilization of services [13].

The WABI women in this study did not seek HTN care regularly primarily because they could not discuss their care or get adequate feedback from their HCPs. They valued a HCP who is willing to listen patiently and consider their opinion in their HTN care plan. This confirms previous findings that immigrant women valued culturally sensitive education and treatment programs that considered their ethnos cultural beliefs $[11,14]$.

The WABI women in this study would prefer HTN programs run by an HCP that lived or worked in Africa. For them, communication mattered in establishing rapport with their medical providers [24].Most of them saw their HCPs only for an annual wellness check, and were reluctant to see the same HCP for HTN management.

Two other factors reported in the literature as contributors to poor utilization of care were not confirmed in this study. One was the remote locations of services[23, 24]; most of these WABI women lived only 1030 minutes away from their HCP's office, and distance did not affect their use of services [23, 24]. Many of the women chose their current HCP because of the convenient location of their clinics. A second factor in why African immigrants failed to seek health care regularly has been reported to be cost of the copayment or lack of health coverage $[16,17]$. In this study the WABI women had medical insurance. It was the dismissive attitude of HCPs to their concerns and questions that was the primary reason for their delay in seeking HTN care. Therefore, this study supports previous recommendations for increased cultural competency among HCPs, and the need for a proper understanding of the various cultural cues' immigrants use in communicating their feelings, opinions, and preferences to their $\operatorname{HCPs}[26,27,28$,$] .$

\section{New Contribution to the Literature}


The factors contributing to health services utilization in this immigrant sub-group did not include lack of health insurance, or distance from services as reported in previous studies. The women in this study were dissatisfied with the quality of care from their HCP and did not utilize available HTN services regularly in spite of their high educational status, health literacy, convenient location of the HTN care facility and their ability to afford the cost of care. All these WABI women viewed having a HCP who is culturally congruent in communication necessary for better utilization of HTN services.

Having the author as the only coder for the themes that emerged from this study is a limitation to this study. Another is the limited demographics of the sample: they were only women and all educated with many of them in the health profession. Therefore, the results are not generalizable to the larger Africanborn immigrant population in the United States.

\section{Conclusion}

The results do suggest that cultural competence training for non-African healthcare providers serving WABI is needed, and the findings from this study could be helpful for larger scale studies, or smaller comparative studies in other regions of the United States.

\section{Abbreviations}

HCP, WABI, HTN, ER, BP, CVD, AA, US

\section{Declarations}

\section{(a) Ethics approval and consent to participate}

The study was reviewed by the Institutional Review Board and approved by the Ethics Review Committee of Walden University in accordance with Walden University dissertation research policy before initiation of the study. All the study participants provided written informed consent before participation in the study. The recruitment and consent form information included consent for publication of their interview responses anonymously.

and Dr Gwenyth Wallen and Dr. Alyssa Todaro Brooks of the National Institutes of Health Nursing Research and Translational Science provided qualitative research mentorship.

\section{(b) Consent for publication}

I confirm that no data have been fabricated or manipulated to support conclusions and both Dr Schwab and Dr Gwenyth Wallen reviewed and gave approval and consent to submit the manuscript.

\section{(c) Availability of data and material}


Interview transcripts are password protected on my personal computer file. I confirm that no data have been fabricated or manipulated to support conclusions.

\section{(d) Competing interests}

The authors declare no competing interests. There is no conflicts of interest to disclose.

\section{(e) Funding}

I did not receive any funding related to the research presented in this manuscript.

\section{(f) Authors Contributions}

The corresponding Author, Dr Assumpta Ude designed, conducted the study and prepared the manuscript. Co-author, Dr Michael Schwab served as the dissertation committee Chair/Methodology Resource.

\section{(g) Acknowledgements}

I acknowledge the other Faculty members of Walden University that served in my dissertation Review Committee: Dr. Amy Wilson (Content and Subject Matter Resource) Dr. Kim Sanders (Independent Faculty Reviewer). I would like to also acknowledge the National Institutes of Health Nursing Research and Translational Science team for reviewing my manuscript and providing qualitative research mentorship, particularly Dr.GwenythWallen and Dr. Alyssa Todaro Brooks. I thank Dr. Ann Marie Matlock and Dr. Deborah Kolakowski for their supervisory guidance.

\section{(h) Corresponding Author's information}

Assumpta O. Ude

National Institute of Health

Clinical Center Nursing Department

Bethesda, Maryland, 20892

Email: Assumpta.ude@nih.gov

\section{References}

1. Centers for Disease Control and Prevention. Facts about Hypertension. 2020 . https://www.cdc.gov/bloodpressure/facts. Accessed 20 Sept. 2020.

2. James PA, Oparil S, Carter BL, Cushman WC, Dennison-Himmelfarb C, Handler J, Lackland DT, LeFevre ML, MacKenzie TD, Ogedegbe O, Smith SC. 2014 evidence-based guideline for the management of high blood pressure in adults: report from the panel members appointed to the Eighth Joint National Committee (JNC 8). Jama. 2014 Feb 5;311(5):507-20. 
3. World Health Organization. Hypertension. 2019. https://www.who.int/news-room/factsheets/detail/hypertension. Accessed 20 Sept. 2020.

4. Centers for Disease Control and Prevention, National Health and Nutrition Examination Survey. Prevalence of hypertension among adults. 2020. https://www.cdc.gov/nchs/data/factsheets/factsheet_nhanes.pdf. Accessed 20 Sept. 2020.

5. Agency for Health Research and Quality. Race, Ethnicity, and Language Data: Standardization for Health Care Quality Improvement. https://www.ahrq.gov/research/findings/final-reports. Accessed 20 Sept. 2020.

6. Sewali B, Harcourt N, Everson-Rose SA, Leduc RE, Osman S, Allen ML, Okuyemi KS. Prevalence of cardiovascular risk factors across six African Immigrant Groups in Minnesota. BMC Public Health. 2015 Dec 1;15(1):411.

7. Commodore-Mensah Y, Samuel LJ, Dennison-Himmelfarb CR, Agyemang C. Hypertension and overweight/obesity in Ghanaians and Nigerians living in West Africa and industrialized countries: a systematic review. Journal of hypertension. 2014 Mar 1;32(3):464-72.

8. Commodore-Mensah Y, Ukonu N, Cooper LA, Agyemang C, Himmelfarb CD. The association between acculturation and cardiovascular disease risk in Ghanaian and Nigerian-born African immigrants in the United States: the Afro-Cardiac Study. Journal of immigrant and minority health. 2018 Oct 1;20(5):1137-46.

9. Ndikum-Moffor FM, Faseru B, Filippi MK, Wei H, Engelman KK. Health status among black Africanborn women in Kansas City: a preliminary assessment. BMC research notes. 2015 Dec 1;8(1):540.

10. Sanon MA, Mohammed SA, McCullagh MC. Definition and management of hypertension among Haitian immigrants: a qualitative study. Journal of health care for the poor and underserved. 2014;25(3):1067.

11. Nataly Agabin BS, Janis Coffın DO. Undocumented and uninsured: aftereffects of the Patient Protection and Affordable Care Act. The Journal of medical practice management: MPM. 2015 Mar 1;30(5):345.

12. Levesque JF, Harris MF, Russell G. Patient-centred access to health care: conceptualising access at the interface of health systems and populations. International journal for equity in health. $2013 \mathrm{Dec}$ 1;12(1):18.

13. Yi S, Elfassy T, Gupta L, Myers C, Kerker B. Nativity, language spoken at home, length of time in the United States, and race/ethnicity: associations with self-reported hypertension. American journal of hypertension. 2014 Feb 1;27(2):237-44.

14. Coulon SM, Wilson DK, Alia KA, Van Horn ML. Multilevel associations of neighborhood poverty, crime, and satisfaction with blood pressure in African-American adults. American journal of hypertension. 2016 Jan 1;29(1):90-5.

15. Yarova LA, Krassen Covan E, Fugate-Whitlock E. Effect of acculturation and health beliefs on utilization of health care services by elderly women who immigrated to the USA from the former Soviet Union. Health Care for Women International. 2013 Dec 1;34(12):1097-115. 
16. Ndukwe EG, Williams KP, Sheppard V. Knowledge and perspectives of breast and cervical cancer screening among female African immigrants in the Washington DC metropolitan area. Journal of Cancer Education. 2013 Dec 1;28(4):748-54.

17. Nwoye A. Understanding and treating African immigrant families: new questions and strategies. Psychotherapy and Politics International. 2009 Jun;7(2):95-107.

18. Sample PU. Census of Population and Housing: Technical Documentation. PUMS/15-US (RV), US Census Bureau, December 2005.[Adobe Systems Portable Document Format (PDF)]. Available: http://www. census. gov/prod/cen2000/doc/pums. pdf; 2000.

19. Glanz K, Rimer BK, Viswanath K, editors. Health behavior: Theory, research, and practice. John Wiley \& Sons; 2015 Jul 1.

20. Penchansky R, Thomas JW. The concept of access: definition and relationship to consumer satisfaction. Medical care. 1981 Feb 1:127-40.

21. Primeau LA. Reflections on self in qualitative research: Stories of family. American Journal of Occupational Therapy. 2003 Jan 1;57(1):9-16.

22. Lincoln Y, Guba E. Naturalistic Inquiry Vol. 75 Sage. Beverly Hills, CA. 1985.

23. Torán-Monserrat P, Cebrià-Andreu J, Arnau-Figueras J, Segura-Bernal J, Ibars-Verdaguer A, MassonsCirera J, Barreiro-Montaña MC, Santamaria-Bayes S, Limón-Ramírez E, Montero-Alia JJ, Pérez-Testor C. Level of distress, somatisation and beliefs on health-disease in newly arrived immigrant patients attended in primary care centres in Catalonia and definition of professional competences for their most effective management: PROMISE Project. BMC family practice. 2013 Dec 1;14(1):54.

24. Wherry LR, Miller S. Early coverage, access, utilization, and health effects associated with the Affordable Care Act Medicaid expansions: a quasi-experimental study. Annals of internal medicine. 2016 Jun 21;164(12):795-803.

25. Coulon SM, Wilson DK, Alia KA, Van Horn ML. Multilevel associations of neighborhood poverty, crime, and satisfaction with blood pressure in African-American adults. American journal of hypertension. 2016 Jan 1;29(1):90-5.

26. White K, Avendaño M, Capistrant BD, Moon JR, Liu SY, Glymour MM. Self-reported and measured hypertension among older US-and foreign-born adults. Journal of immigrant and minority health. 2012 Aug 1;14(4):721-6.

27. White K, Borrell LN, Wong DW, Galea S, Ogedegbe G, Glymour MM. Racial/ethnic residential segregation and self-reported hypertension among US-and foreign-born blacks in New York City. American journal of hypertension. 2011 Aug 1;24(8):904-10.

28. Kendrick J, Nuccio E, Leiferman JA, Sauaia A. Primary care providers perceptions of racial/ethnic and socioeconomic disparities in hypertension control. American journal of hypertension. 2015 Sep 1;28(9):1091-7.

\section{Figures}


1. Describe your experiences seeking medical help for hypertension in the past year.

2. Describe your experiences with access to health services

3. How do you get to your health care facility or doctor's office?

4. Describe the reasons you sought health care in the past one year.

5. Describe your experiences receiving medical treatment in a health care facility.

6. What do you think about the distance from your house to your local hospital?

7. Describe how you learned about where to go for healthcare.

8. Describe what you expect from a HTN healthcare practice or program.

9. Describe what you consider a suitable health care service for HTN.

10. Describe other dimensions or components you desire in a HTN health program.

11. What is your opinion about what should constitute a HTN program for WABI?

\section{Figure 1}

Selected interview questions 